\title{
Treatment of acute high-grade acromioclavicular joint dislocation
}

\author{
Jeung Yeol Jeong ${ }^{1}$, Yong-Min Chun ${ }^{2}$ \\ ${ }^{1}$ Department of Orthopedic Surgery, Hallym University Dongtan Sacred Heart Hospital, Hallym University College of Medicine, Hwaseong, Korea \\ ${ }^{2}$ Department of Orthopedic Surgery, Arthroscopy and Joint Research Institute, Severance Hospital, Yonsei University College of Medicine, Seoul, Korea
}

Acromioclavicular (AC) joint dislocations account for about $9 \%$ of shoulder injuries. Among them, acute high-grade injury following high-energy trauma accounts for a large proportion of patients requiring surgical treatment. However, there is no gold standard procedure for operative treatment of acute high-grade AC joint injury, and several different procedures have been used for this purpose in clinical practice. This review article summarizes the most recent and relevant surgical options for acute high-grade AC joint dislocation patients and the outcomes of each treatment type.

Keywords: Acute high-grade acromioclavicular joint injuries; Treatments; Shoulder

\section{INTRODUCTION}

Numerous surgical techniques to treat acute high-grade acromioclavicular (AC) joint dislocation have been reported in previous studies [1-5]. Opening fixation techniques, such as using a hook plate or Bosworth screw, are still widely used. Arthroscopic fixation techniques have recently been developed and used in a variety of ways to treat AC joint dislocation [6]. However, the optimal surgical treatment of these options is still unclear.

The stability of the AC joint is maintained mainly by the coracoclavicular (CC) and AC ligaments. The CC ligament is composed of conical and trapezoid ligaments, which play an important role as vertical stabilizers of the AC joint. Surgical treatment is recommended for Rockwood Type III and V injuries due to AC joint instability caused by a complete rupture of the CC and AC ligaments by higher energy trauma [7].

Hook plate fixation is a reliable and widely used treatment for AC joint dislocations. However, the role of the clavicle hook plate is to produce nonanatomical reduction of the AC joint, which may have negative effects on the shoulder rehabilitation process and can lead to loss of reduction following plate removal. In addition, this technique has the disadvantage of requiring a second operation to remove the plate. Arthroscopically, cortical button fixation has recently been introduced and has shown successful results, including several advantages over open procedures [8]. However, this arthroscopic fixation technique is concerning regarding its ability to provide horizontal stability; several complications related to metals have been reported, such as

Received: April 21, $2020 \quad$ Accepted: May 6, 2020

Correspondence to: Yong-Min Chun

Department of Orthopedic Surgery, Arthroscopy and Joint Research Institute, Severance Hospital, Yonsei University College of Medicine, 50-1 Yonseiro, Seodaemun-gu, Seoul 03722, Korea

Tel: +82-2-2228-2180, Fax: +82-2-363-1139, E-mail: min1201@hanmail.net, ORCID: https://orcid.org/0000-0002-8147-6136

Financial support: None.

Conflict of interest: None.

Copyright@ 2020 Korean Shoulder and Elbow Society. All Rights Reserved.

This is an Open Access article distributed under the terms of the Creative Commons Attribution Non-Commercial License (http://creativecommons.org/licenses/by-nc/4.0/) which permits unrestricted non-commercial use, distribution, and reproduction in any medium, provided the original work is properly cited. 
loss of CC reduction and risk of fracture of the clavicle or coracoid process $[1,9]$.

Recently, Lee et al. [5] introduced an arthroscopic CC fixation technique that uses multiple soft anchor knots to overcome these complications and reported satisfactory clinical outcomes. Their technique ensured both horizontal and vertical stability to the AC joint while maintaining anatomic fixation [5]. Today, more than 150 surgical and conservative treatment options have been described to treat AC joint dislocations, although many are controversial. The present review summarizes the currently available data regarding surgical options for acute high-grade AC joint dislocation.

\section{CLASSIFICATION}

The most commonly used classification for AC joint dislocation is the Rockwood classification system [10]. This approach is based on radiological findings and classifies AC joint dislocations into six types. Low-energy trauma injuries, which are classified as type I or type II injuries, are treated conservatively using a Kenny-Howard brace [11]. In contrast, high-energy trauma injuries, such as type IV, type V, and type VI injuries, are treated surgically [12], while the treatment for type III injuries is still being debated [13].

\section{SURGICAL PROCEDURES}

\section{Hook Plate Fixation}

$\mathrm{AC}$ joint fixation allows time for the native $\mathrm{AC}$ and $\mathrm{CC}$ ligaments to heal in place by reducing the $\mathrm{AC}$ joint and maintaining the reduced AC joint. Hook plate fixation is one method of primary fixation across the AC joint (Fig. 1). In this fixation method, the hook portion of the plate is positioned beneath the acromion, and the plate is then fixed to the clavicle with screws to maintain adequate reduction of the $\mathrm{AC}$ joint. The technique can be used to treat acute injuries and may be combined with ligament reconstruction for chronic injuries with good short-term outcomes. Kienast et al. [14] used AC hook plate fixation to treat 225 patients with Rockwood type III-V AC joint dislocations and reported excellent or good outcomes in $89 \%$ of patients; however, the overall rate of complications was relatively high (10.6\%). It is not rare for hook plate fixation to result in serious complications, including upward cutting of the hook through the acromion [15], subacromial osteolysis [16], fracture [17], AC joint osteoarthritis, subacromial impingement, and rotator cuff tears [18]. In vivo analyses of AC joint motion after hook plate fixation have indicated that clavicular motion and $\mathrm{AC}$ joint biomechanics change significantly after hook plate fixation [19]. The main disadvantage of this surgical procedure is the need for a second surgery to remove the implanted hardware.

\section{Bosworth Screw Fixation}

In 1941, Bosworth [20] introduced a fixation technique involving placement of a screw between the clavicle and the coracoid. Typically, a $6.5-\mathrm{mm}$ partially threaded cancellous screw is used. Most surgeons favor open screw insertion, as percutaneous techniques are associated with a high rate of technical failure (32\%) [21]. According to Rockwood et al. [22], five types of motion between the coracoid and the clavicle can lead to fatigue or failure of the implant over time. Because of the high rate of hardware migration and screw breakage over time, reoperation is usually required between 8 and 12 weeks after the initial sur-
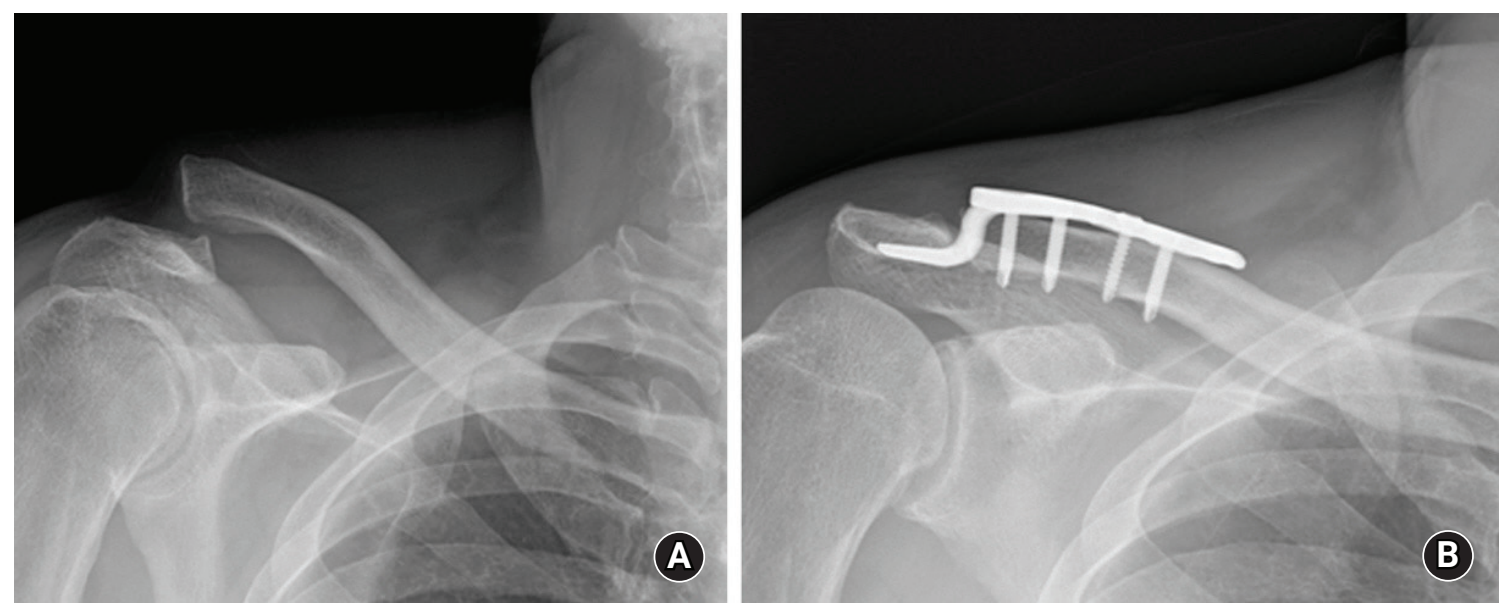

Fig. 1. Serial radiographs from a 45-year-old man treated with reconstruction of an acute acromioclavicular joint separation of Rockwood type $\mathrm{V}$ using a hook plate showing good joint reduction and maintenance of joint reduction. (A) Preoperative. (B) Postoperative. 
gical procedure [23].

\section{Arthroscopic Fixation of the CC Joint}

Arthroscopic-assisted procedures with CC suspension devices aim to increase the healing ability of torn AC and CC ligaments and reduce the $\mathrm{CC}$ distance. In the management of AC joint injuries, arthroscopy-assisted procedures provide several advantages over open procedures. These techniques offer superior visualization of the base of the coracoid and require less soft tissue dissection and smaller incisions than open procedures [24]. Additionally, arthroscopic techniques have the theoretical benefit of allowing the surgeon to identify and treat associated injuries within the glenohumeral joint and subacromial space [25].

\section{The TightRope/EndoButton/Dog Bone technique}

A prosthetic CC suspension device, such as the TightRope device (Arthrex, Naples, FL, USA), can also be implanted (Fig. 2). This device contains titanium buttons placed on top of the clavicle and under the coracoid that are connected with a continuous loop of no. 5 FiberWire suture (Arthrex). A similar device, the EndoButton device (Smith \& Nephew, Memphis, TN, USA), was also used with a no. 5 Ethibond suture (Ethicon Inc., Somerville, NJ, USA) (Fig. 3). The TightRope device was based on the principles of the EndoButton system [26]. Subsequently, the Dog Bone device (Arthrex) (Fig. 4), which is similar to the TightRope/EndoButton devices, has also been introduced [27].

Using these single metallic suspension devices anchored at the
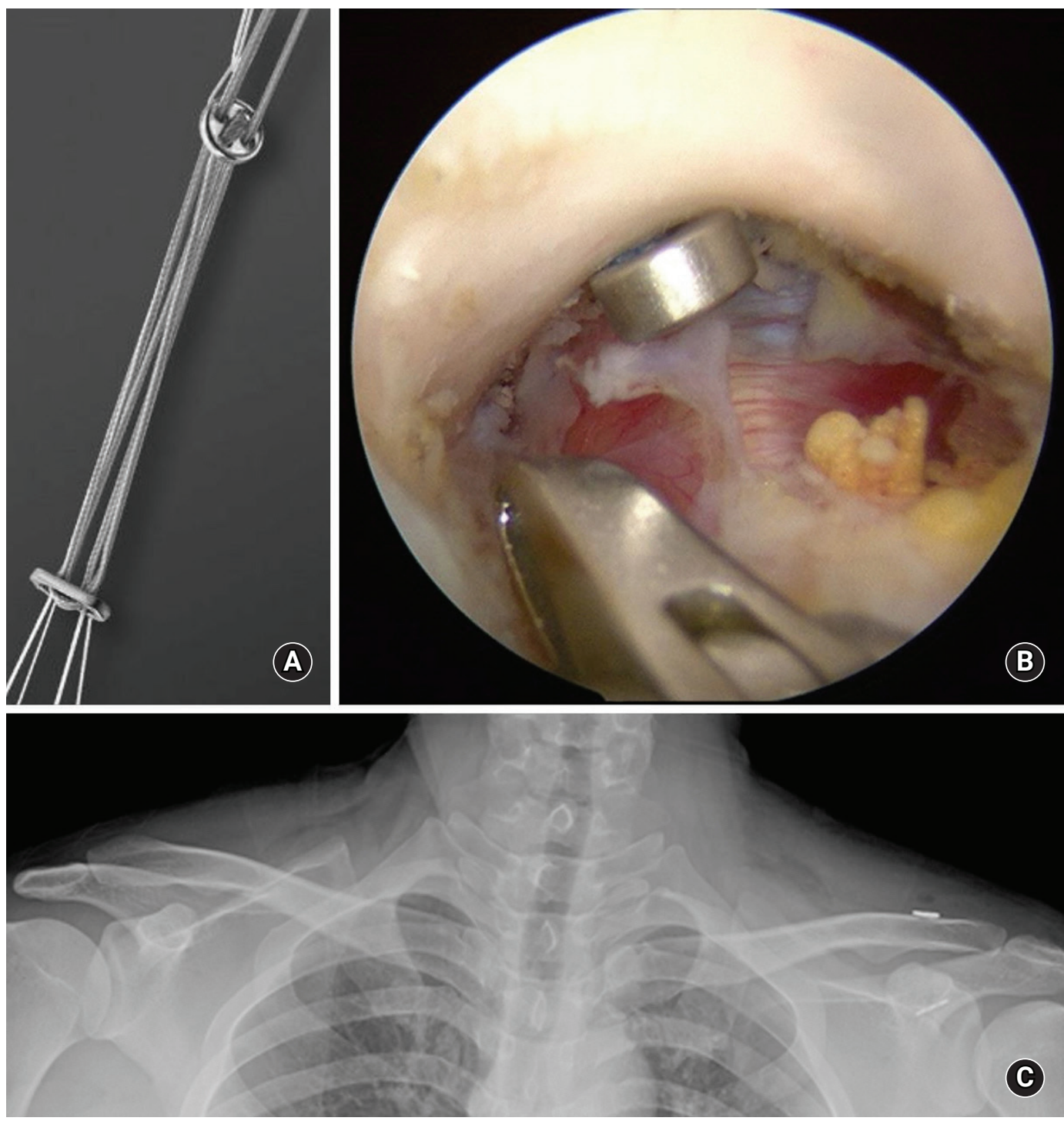

Fig. 2. Arthroscopic-assisted procedures with a coracoclavicular (CC) suspension device. (A, B) TightRope device. (B) The subacromial space viewed through the anterolateral portal. Fixation findings of the TightRope anchored under the base of the coracoid process. (C) A postoperative anteroposterior radiograph revealing a slightly over-reduced CC interval and acromiohumeral joint. 
isometric point of the CC ligament, good clinical results have been reported in many other studies; however, the risk of secondary subluxation is a concern [28]. The most commonly reported complication was hardware migration into the clavicle, coracoid, or both. The rate of migration was as high as $89 \%$ as reported by Scheibel et al. [29]. In addition, many patients complain of persistent symptoms after surgery related to hardware irritation over the superior clavicle fixation site [9].

Since vertical placement of these single metallic suspension devices does not replicate the normal orientation of the CC ligaments, this non-anatomic technique has recently been criticized in biomechanical studies [30]. Therefore, while vertical stability may be restored, horizontal instability may persist [31]. Theoretically, the use of two or more vertical stabilizers along the course

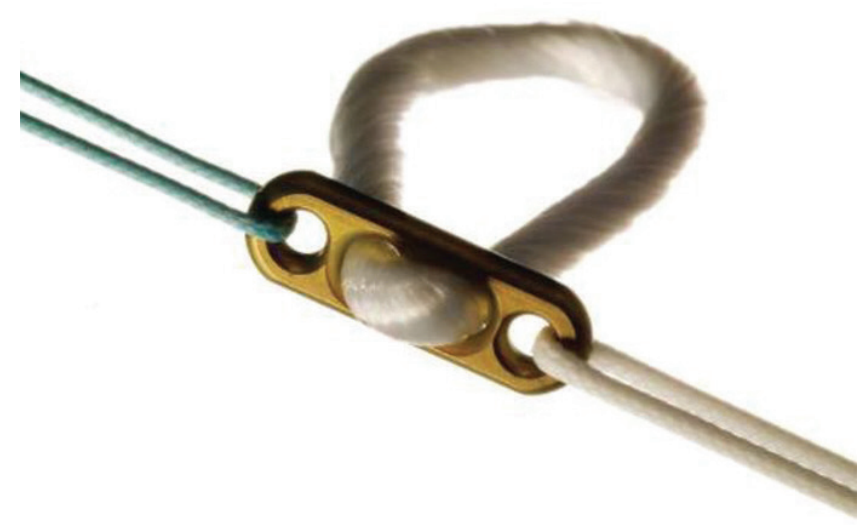

Fig. 3. A coracoclavicular suspension device: the EndoButton device. of the CC ligament can better restore the anatomical and biomechanical properties of the natural ligaments [30]. Scheibel et al. [29] published good to excellent early clinical results using arthroscopic-assisted techniques with two TightRope devices in 28 patients with acute AC joint dislocation. In addition, Venjakob et al. [32] reported reliable stability of AC joints in $96 \%$ of patients in a study of arthroscopic-assisted, double EndoButton device procedures to treat $\mathrm{AC}$ joint dislocation with a mean follow-up duration of 58 months [32].

Despite these favorable results, the use of two metallic CC suspension devices risks fracture of the clavicle or coracoid process due to the non-negligible diameter of the drill holes, $4.0 \mathrm{~mm}$ [3335]. Martetschläger et al. [36] showed that $20 \%$ of the fractures of the clavicle or coracoid process were related to complications resulting from technical errors in the drilling technique. Despite these technical surgical problems, the TightRope/EndoButton/ Dog Bone techniques had the lowest rate of radiographic failure at only $5 \%$ of patients with recurrent dislocation.

\section{Multiple all-suture anchor technique}

CC suspension devices, such as the 1.8-mm Y-Knot Flex All-suture Anchor (ConMed Linvatec, Utica, NY, USA), were used. In contrast with procedures that use metal knots, soft knots are anchored at the bottom of the coracoid process at the entrance to the tunnel. The use of three vertical stabilizers rather than a single vertical stabilizer was intended to restore horizontal stability as well as vertical stability, as in the suspension bridge principle (Fig. 5). It is important to create small-width bone tunnels to re-

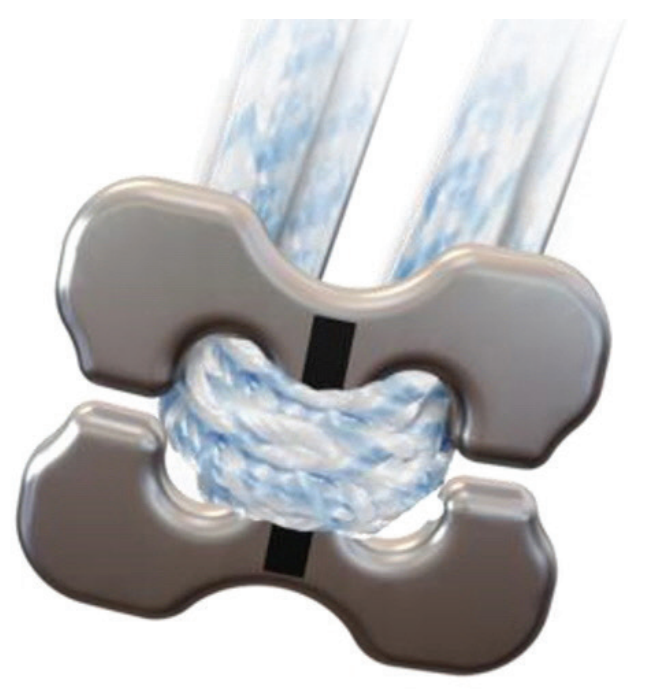

A

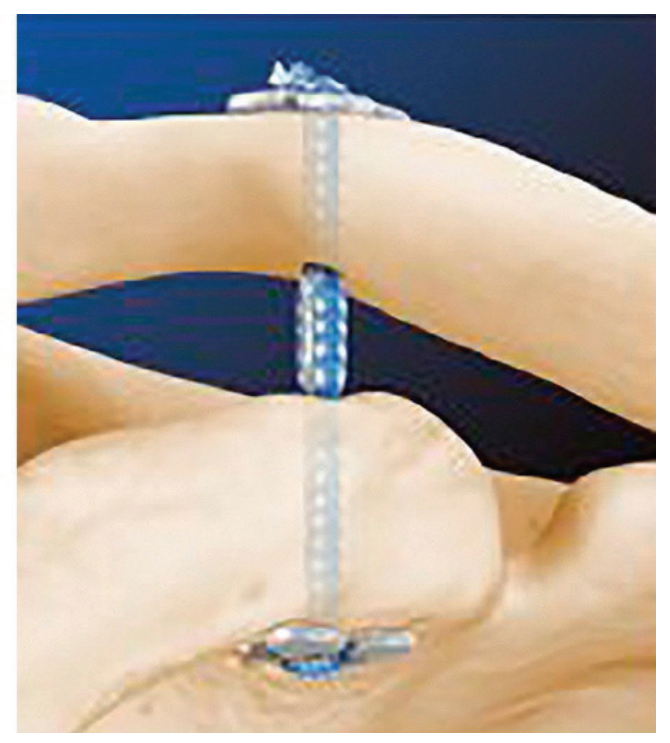

B

Fig. 4. A coracoclavicular (CC) suspension device: (A) the Dog-Bone device, (B) illustration of CC fixation using a Dog Bone device. 
duce the risk of clavicle or coracoid process fractures [37]. Recently, Lee et al. [5] reported satisfactory clinical outcomes at a mean follow-up of two years in 27 patients with acute high-grade AC joint injury treated with an arthroscopic CC fixation technique using multiple soft anchor knots. These outcomes are likely due to the small tunnel width and multiple strands used, which allow for safe fixation while minimizing complications of metal- lic fixation and providing strong vertical and horizontal stability. It is important to note that the learning curve for this procedure is steep because it is technically demanding. Nevertheless, according to currently available biomechanical and clinical evidence, multiple all-suture anchor fixation can be considered a feasible and reliable treatment strategy for AC dislocation.
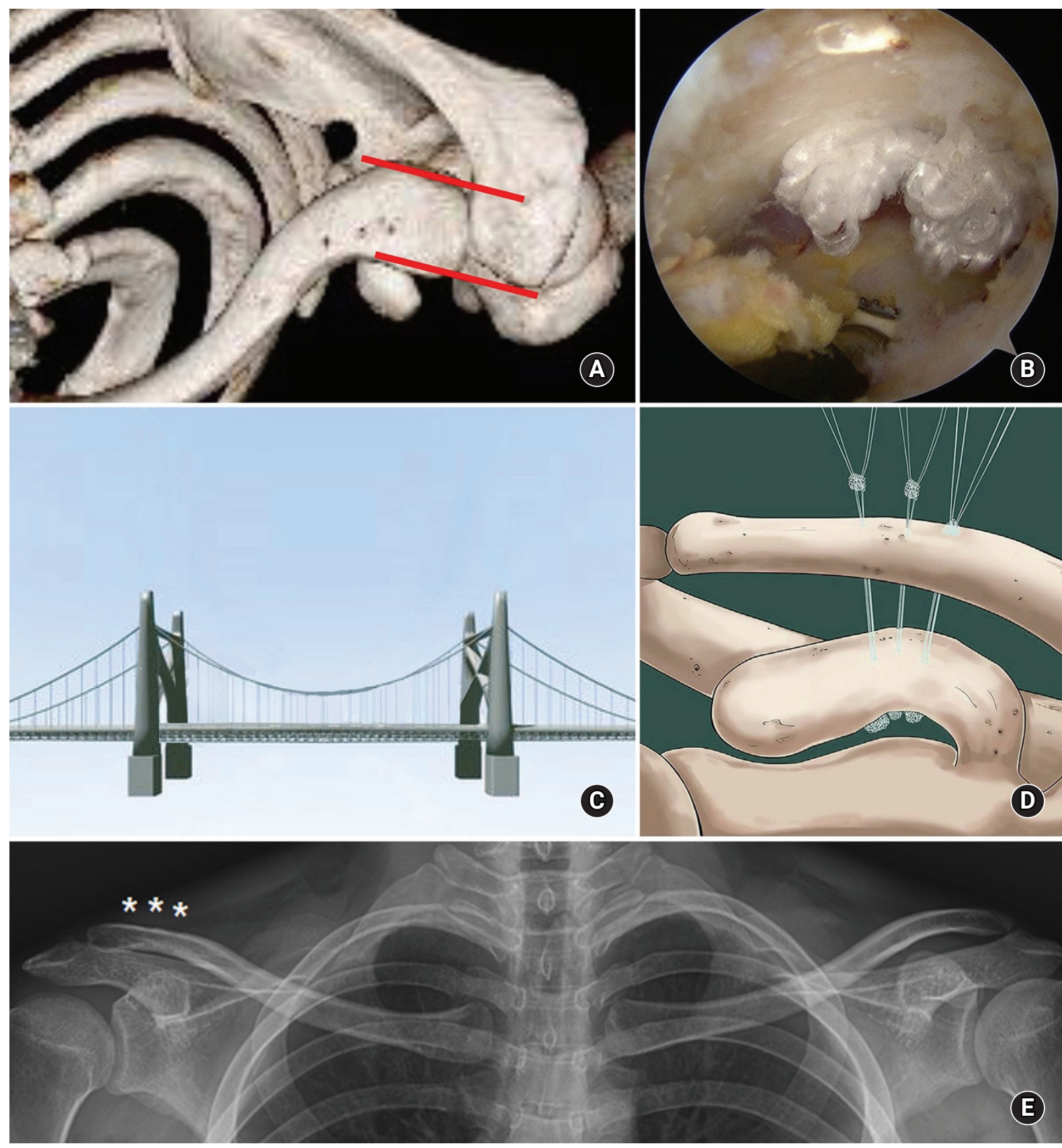

Fig. 5. (A) A computed tomography image after three-dimensional reconstruction shows correction of horizontal instability of the left clavicle. The red lines show the horizontal stability of the acromioclavicular joint. (B) The arthroscopic finding of multiple knots anchoring under the base of the coracoid process. (C) The suspension bridge. (D) An illustration of coracoclavicular (CC) fixation using three vertical stabilizers. This method can restore horizontal stability and vertical stability, as in the suspension bridge principle. (E) Bilateral anteroposterior plain radiograph at final follow-up after surgery, showing maintenance of the CC distance. Asterisks indicate the clavicle tunnels. 


\section{CONCLUSION}

AC joint dislocation is a relatively common injury in the general population. A large proportion of these patients demonstrate acute high-grade AC joint injury that requires surgical treatment. Surgical treatment methods have made great progress in the past 30 years, and various surgical procedures are suitable for treatment of AC joint injuries. However, no gold standard procedure has been established. It is therefore vital to consider various surgical treatments depending on patient age and physical needs and the surgeon's proficiency.

\section{ORCID}

Jeung Yeol Jeong

Yong-Min Chun

https://orcid.org/0000-0001-8145-1302 https://orcid.org/0000-0002-8147-6136

\section{REFERENCES}

1. Pan Z, Zhang H, Sun C, Qu L, Cui Y. Arthroscopy-assisted reconstruction of coracoclavicular ligament by Endobutton fixation for treatment of acromioclavicular joint dislocation. Arch Orthop Trauma Surg 2015;135:9-16.

2. Cho CH, Kim BS, Kwon DH. Importance of additional temporary pin fixation combined coracoclavicular augmentation using a suture button device for acute acromioclavicular joint dislocation. Arch Orthop Trauma Surg 2016;136:763-70.

3. Millett PJ, Warth RJ, Greenspoon JA, Horan MP. Arthroscopically assisted anatomic coracoclavicular ligament reconstruction technique using coracoclavicular fixation and soft-tissue grafts. Arthrosc Tech 2015;4:e583-7.

4. Shetty NS, Yoo YS, Kim DY, Lee SS, Jeong US. Open anatomical coracoclavicular ligament reconstruction using a tendon graft with an Endobutton loop. Acta Orthop Belg 2009;75:828-31.

5. Lee SJ, Yoo YS, Kim YS, et al. Arthroscopic coracoclavicular fixation using multiple low-profile devices in acute acromioclavicular joint dislocation. Arthroscopy 2019;35:14-21.

6. Cetinkaya E, Arıkan Y, Beng K, Mutlu H, Yalçınkaya M, Üzümcügil O. Bosworth and modified Phemister techniques revisited: a comparison of intraarticular vs extraarticular fixation methods in the treatment of acute Rockwood type III acromioclavicular dislocations. Acta Orthop Traumatol Turc 2017;51:455-8.

7. Yin J, Yin Z, Gong G, Zhu C, Sun C, Liu X. Comparison of hook plate with versus without double-tunnel coracoclavicular ligament reconstruction for repair of acute acromioclavicular joint dislocations: a prospective randomized controlled clinical trial. Int J Surg 2018;54(Pt A):18-23.

8. Issa SP, Payan C, Le Hanneur M, Loriaut P, Boyer P. Arthroscopically assisted reduction of acute acromioclavicular joint dislocation using a single double-button device: medium-term clinical and radiological outcomes. Orthop Traumatol Surg Res 2018;104:33-8.

9. Woodmass JM, Esposito JG, Ono Y, et al. Complications following arthroscopic fixation of acromioclavicular separations: a systematic review of the literature. Open Access J Sports Med 2015;6:97-107.

10. Rockwood C, Williams G, Young D. Disorders of the acromioclavicular joint. In: Rockwood CA, ed. The shoulder. 3rd ed. Philadelphia, PA: WB Saunders; 2004. p. 521-95.

11. Tauber M. Management of acute acromioclavicular joint dislocations: current concepts. Arch Orthop Trauma Surg 2013; 133:985-95.

12. Greiner S, Braunsdorf J, Perka C, Herrmann S, Scheffler S. Mid to long-term results of open acromioclavicular-joint reconstruction using polydioxansulfate cerclage augmentation. Arch Orthop Trauma Surg 2009;129:735-40.

13. Ceccarelli E, Bondì R, Alviti F, Garofalo R, Miulli F, Padua R. Treatment of acute grade III acromioclavicular dislocation: a lack of evidence. J Orthop Traumatol 2008;9:105-8.

14. Kienast B, Thietje R, Queitsch C, Gille J, Schulz AP, Meiners J. Mid-term results after operative treatment of rockwood grade III-V acromioclavicular joint dislocations with an AC-hookplate. Eur J Med Res 2011;16:52-6.

15. Gstettner C, Tauber M, Hitzl W, Resch H. Rockwood type III acromioclavicular dislocation: surgical versus conservative treatment. J Shoulder Elbow Surg 2008;17:220-5.

16. Chiang CL, Yang SW, Tsai MY, Kuen-Huang Chen C. Acromion osteolysis and fracture after hook plate fixation for acromioclavicular joint dislocation: a case report. J Shoulder Elbow Surg 2010;19:e13-5.

17. Hoffler CE, Karas SG. Transacromial erosion of a locked subacromial hook plate: case report and review of literature. J Shoulder Elbow Surg 2010;19:e12-5.

18. Bahk MS, Kuhn JE, Galatz LM, Connor PM, Williams GR Jr. Acromioclavicular and sternoclavicular injuries and clavicular, glenoid, and scapular fractures. J Bone Joint Surg Am 2009;91:2492-510

19. Kim YS, Yoo YS, Jang SW, Nair AV, Jin H, Song HS. In vivo analysis of acromioclavicular joint motion after hook plate fixation using three-dimensional computed tomography. J Shoulder Elbow Surg 2015;24:1106-11.

20. Bosworth BM. Acromioclavicular separation: new method of repair. Surg Gynecol Obstet 1941;73:866-71. 
21. Tsou PM. Percutaneous cannulated screw coracoclavicular fixation for acute acromioclavicular dislocations. Clin Orthop Relat Res 1989;(243):112-71.

22. Rockwood CA, Green DP, Bucholz RW. Rockwood and Green's fractures in adults. 6th ed. Philadelphia, PA: Lippincott Williams \& Wilkins; 2006. p. 672-695.

23. Kwon YW, Iannotti JP. Operative treatment of acromioclavicular joint injuries and results. Clin Sports Med 2003;22:291-300.

24. Tomlinson DP, Altchek DW, Davila J, Cordasco FA. A modified technique of arthroscopically assisted AC joint reconstruction and preliminary results. Clin Orthop Relat Res 2008;466:63945.

25. Rolla PR, Surace MF, Murena L. Arthroscopic treatment of acute acromioclavicular joint dislocation. Arthroscopy 2004;20:662-8.

26. Lim YW, Sood A, van Riet RP, Bain GI. Acromioclavicular joint reduction, repair and reconstruction using metallic buttons: early results and complications. Tech Shoulder Elb Surg 2007;8:213-21.

27. Braun S, Imhoff AB, Martetschlaeger F. Primary fixation of acromioclavicular joint disruption. Oper Tech Sports Med 2014;22:221-26.

28. Shin SJ, Kim NK. Complications after arthroscopic coracoclavicular reconstruction using a single adjustable-loop-length suspensory fixation device in acute acromioclavicular joint dislocation. Arthroscopy 2015;31:816-24.

29. Scheibel M, Dröschel S, Gerhardt C, Kraus N. Arthroscopically assisted stabilization of acute high-grade acromioclavicular joint separations. Am J Sports Med 2011;39:1507-16.

30. Walz L, Salzmann GM, Fabbro T, Eichhorn S, Imhoff AB. The anatomic reconstruction of acromioclavicular joint dislocations using 2 TightRope devices: a biomechanical study. Am J Sports Med 2008;36:2398-406.

31. Mazzocca AD, Santangelo SA, Johnson ST, Rios CG, Dumonski ML, Arciero RA. A biomechanical evaluation of an anatomical coracoclavicular ligament reconstruction. Am J Sports Med 2006;34:236-46.

32. Venjakob AJ, Salzmann GM, Gabel F, et al. Arthroscopically assisted 2-bundle anatomic reduction of acute acromioclavicular joint separations: 58-month findings. Am J Sports Med 2013;41:615-21.

33. Fahmy FS, Fathi H, ElAttar M. Clinical outcomes of arthroscopic assisted fixation of acute high grade acromioclavicular joint disruption. J Orthop 2019;16:133-6.

34. Lu D, Wang T, Chen H, Sun LJ. A comparison of double Endobutton and triple Endobutton techniques for acute acromioclavicular joint dislocation. Orthop Traumatol Surg Res 2016;102:891-5.

35. Seo JB, Lee DH, Kim KB, Yoo JS. Coracoid clavicular tunnel angle is related with loss of reduction in a single-tunnel coracoclavicular fixation using a dog bone button in acute acromioclavicular joint dislocation. Knee Surg Sports Traumatol Arthrosc 2019;27:3835-43.

36. Martetschläger F, Horan MP, Warth RJ, Millett PJ. Complications after anatomic fixation and reconstruction of the coracoclavicular ligaments. Am J Sports Med 2013;41:2896-903.

37. Dyrna F, de Oliveira CC, Nowak M, et al. Risk of fracture of the acromion depends on size and orientation of acromial bone tunnels when performing acromioclavicular reconstruction. Knee Surg Sports Traumatol Arthrosc 2018;26:275-84. 